\title{
Biogeochemical cycling of nutrient elements following the early Mesoproterozoic oxygenation event
}

\author{
XUN WANG ${ }^{1}$, XIANGKUn ZhU ${ }^{1 *}$, KAN ZHANG ${ }^{1}$ \\ ${ }^{1}$ MNR Key Laboratory of Isotope Geology, MNR Key \\ Laboratory of Deep-Earth Dynamics, Institute of Geology, \\ Chinese Academy of Geological Sciences, Beijing \\ 100037, China $(*$ correspondence: \\ xiangkunzhu@163.com)
}

Environmental and evolutionary stasis has long been considered to characterise the mid-Proterozoic (ca. 1.8-0.8 $\mathrm{Ga}$ ), and therefore this period is also referred to as "Boring Billion" or "Earth's middle age". However, increasing paleontological and geochemical studies, especially the discoveries of the decimetre-scale multicellular eukaryotes and the oceanic oxygenation event from the Mesoproterozoic Gaoyuzhuang Formation in North China indicate that the period of the "Boring Billion" is vigorous rather than dull [1, 2]. In addition, there is no evidence from the fossil record for continuous diversification of eukaryotes for a long period following this oxygenation event. The oxygenation event might restrict the evolution of multicellular eukaryotes by influencing the biogeochemical cycles of nutrient elements.

In order to reveal the environmental effects of this oxygenation event, and try to explore the co-evolution relationship of the earth's early life and environment, we have conducted iron isotopes and bio-essential elements (Fe, Mn, Mo, P, etc.) studies on the carbonate rocks of the Gaoyuzhuang Formation in the Jixian section, North China. The $\delta^{56} \mathrm{Fe}$ and relevant nutrient elements contents have similar variation trends across the oxygenation event, and namely they all decrease along with the oxygenation event and increase soon at the fossil-bearing interval, but decrease again above this interval.

Our results suggest that sufficient supplies of nutrient elements through expansion of oxygenated environments might drive the flourishing of eukaryotes, but subsequent scarcity of nutrient elements might hinder the further evolution of eukaryotes.

[1] Zhu et al. (2016) Nat. Commun. 7, 11500. [2] Zhang et al. (2018) Nat. Geosci. 11, 345-350. 